\title{
Sentinel Node Biopsy or Neck Dissection for Early- Stage Oral Cancer For Long Term Follow-Up: Matched-Pair Analysis for pNO Necks
}

\section{Carlos Takahiro Chone ( $\nabla$ cchone@icloud.com )}

State University of Campinas: Universidade Estadual de Campinas https://orcid.org/0000-0002-42174629

Guilherme M. de Carvalho

State University of Campinas: Universidade Estadual de Campinas

\section{Maria Kruschewsky}

State University of Campinas: Universidade Estadual de Campinas

Agricio N. Crespo

State University of Campinas: Universidade Estadual de Campinas

Elba C. Etchebehere

State University of Campinas: Universidade Estadual de Campinas

Albina Altemani

State University of Campinas: Universidade Estadual de Campinas

\section{Research}

Keywords: sentinel lymph node biopsy, lymphatic metastasis, squamous cell carcinoma, oral cavity, neck dissection

Posted Date: June 23rd, 2021

DOI: https://doi.org/10.21203/rs.3.rs-617849/v1

License: (c) (1) This work is licensed under a Creative Commons Attribution 4.0 International License. Read Full License 


\section{Abstract}

Background: Oral cancer spreads preferentially through lymphatics with a high rate of micrometastases. We studied the rate of neck recurrence in patients with T1/T2 squamous cell carcinoma (SCC) of oral cavity with clinically negative necks (CNO) submitted to elective neck dissection (END) or sentinel lymph node biopsy (SLNB) with a histopathologically negative specimen of END (pNO) or sentinel nodes (SN).

Methods: Prospective study matched paired with a retrospective control group. We studied forty-three patients: 25 in the SLNB group and 18 in the control group (END), and compared both patient cohorts, with negative lymph node metastases with more than five years of follow-up. We matched both groups by gender, age, site, stage, pathological status of the primary lesion, adjuvant treatment, length of followup by Odds ratio analysis with $95 \%$ confidence interval and t-test without significant difference all categories $(p>0.05)$.

Results: Both SLNB and END groups had a similar recurrence rate in the neck, without significant difference.

Conclusions: Elective neck dissection may be unnecessary in this study population when SN comes out without metastases after extensive histopathological evaluation.

\section{Introduction}

Head and neck squamous cell carcinoma spreads preferentially through the lymphatic system and plays a significant role in decreasing survival ${ }^{1,2}$. Some controversy remains as observation and therapeutic neck dissection or elective neck dissection for clinically N0 necks(cNO). CT scan, MR, or PET CT for evaluation of micrometastases had a high rate of false-negative and positive ${ }^{3-8}$. Histopathological examination of the surgical specimen following neck dissection is considered the gold standard method for neck staging ${ }^{9}$. We must perform neck dissection in patients whose primary lesion has an expected rate of lymphatic metastases higher than $20 \%^{1,2}$. Even patients with early SCC of the oral cavity, more than two millimeters of depth, possess this risk of metastasis, and elective neck dissection (END) must be performed ${ }^{10-12}$. Neck dissection, in addition to resection of the primary tumor, increases surgical length and morbidity, but END has a survival advantage over wait and sees policy ${ }^{13,14}$.

Thus, sentinel lymph node biopsy (SLNB) could better stage neck in oral cancer patients with cN0 necks. This technique has high sensitivity and negative predictive value for early-stage (T1 and T2) oral cancer in meta-analysis and a large prospective multicentric trial ${ }^{15-22}$.

In cohorts with subsequent END after negative SLNB, only 3 to $5 \%$ were found to have additional metastatic lymph nodes in the surgical specimen. It suggests a low probability of neck recurrence after SLNB without neck dissection when the sentinel node is histopathological negative ${ }^{23-25}$. This recurrence 
rate would be lower than reported in the literature following selective I-III neck dissection (of up to $10 \%$ ) ${ }^{26}$, even after radical neck dissection in pNO necks $(6.7-18 \%)^{27,28}$.

We compared the rate of neck recurrence for two treatment modalities for patients with early-stage SCC of the oral cavity (T1N0 or T2N0). The treatments were excision of the primary lesion with END versus the excision of the primary lesion with SLNB, without subsequent neck dissection when SLNB came out negatively on the permanent section after extensive pathological analysis.

\section{Materials And Methods}

We included only patients with SCC (squamous cell carcinoma) of the oral cavity, confirmed by histopathological examination at our institution from 2010 to 2012. We used the AJCC Eighth Edition for the staging of the primary lesions and $\mathrm{neck}^{29}$. All participants were radiologically negative for lymphatic metastases by multi-slice CT scan with 128 detectors. Consecutive patients submitted to SLNB, which come out negative after extensive histopathological evaluation, were prospectively followed without subsequent neck dissection. Ethical Committee of XXXXXX approved the study under CAAE:0392.0.146.000-07. All participants signed informed consent.

Only negative sentinel lymph node patients without local recurrences were included in statistical analysis to avoid primary recurrence bias.

Patients with positive margins on a permanent section (despite negative results in frozen section), perineural invasion, or vascular emboli were treated with adjuvant radiation therapy on primary tumor bed and neck.

We used two peritumoral injections of technetium labeled nanocolloid for SLNB.

Lymphoscintigraphy and SPEC-CT were performed in all cases. The neck skin was marked accordingly, and a gamma probe was used to identify the sentinel lymph node intraoperatively. We obtained step serial sections at each 150 um of the sentinel lymph node stained with hematoxylin-eosin, and subsequently, immunohistochemistry for cytokeratin AE-1/AE-3 in negative SLNB on HE.

All patients were followed postoperatively with a CT scan every six months for the first two years and yearly.

The control group submitted to END was collected with reviewed medical charts of all consecutive patients with T1/T2 oral cancer, cN0 necks. All with radiologically negative necks, from 2000 to 2012 submitted to END of levels I to III. All pathological evaluation was performed with an extensive evaluation of all paraffin embedded blocks with step serial section of $150 \mathrm{um}$.

Both groups were match-paired by age, gender, stage, site, histopathological status of the primary lesion and neck dissection specimen, adjuvant treatment, and follow-up length. Only patients with negative surgical specimens for lymphatic metastases were included for pairing, without local recurrences. 
Statistics were performed via IBM SPSS Statistics 17 (Windows) software. The odds ratio was used to compare groups by gender, stage, site, adjuvant treatment, and recurrence rate and T-test for continuous categories of age and length of follow-up. P-values $<0.05$ were considered statistically significant.

\section{Results}

Our study comprised 43 patients, 25 of them in the SLNB group and 18 in the control group (END), as detailed in Table 1. 
Table 1

Comparison of clinical and histopathological features of END and SLNB groups

\section{END SLNB p-value}

Gender

\begin{tabular}{llll} 
male & 16 & 23 & OR $=0.70(95 \% \mathrm{Cl}: 0.0886$ to $5.4649 ; p=0.73)$ \\
\cline { 1 - 3 } female & 2 & 2 & \\
\cline { 1 - 3 } Age ys(SD ys) & $58.1(5.4)$ & $58.9(6.4)$ & $\begin{array}{l}\text { Difference }=-0.8(95 \% \mathrm{Cl}: 0.4430 \text { to } 2.8430 ; p=0.10 ; \mathrm{t} \text { - } \\
\text { test })\end{array}$
\end{tabular}

Stage

$\begin{array}{llll}\text { pT1 } & 4 & 6 & \text { OR }=0.90(95 \% \mathrm{Cl}: 0.2141 \text { to } 3.8236 ; \mathrm{p}=0.89) \\ \text { pT2 } & 14 & 19 & \end{array}$

Site

\begin{tabular}{|c|c|c|c|}
\hline tongue & 18 & 25 & $\mathrm{OR}=1.58(95 \% \mathrm{Cl}: 0.3377$ to $7.3831 ; \mathrm{p}=0.56)$ \\
\hline Average length of & $5.8 y s$ & $6.9 y s$ & $\begin{array}{l}\text { Difference }=0.9(95 \% \mathrm{Cl}:-0.1806 \text { to } 1.9806 ; \mathrm{p}=0.10 ; \mathrm{t}- \\
\text { test })\end{array}$ \\
\hline follow-up years & (2.2) & (1.3) & \\
\hline
\end{tabular}

$S D$

\begin{tabular}{lll}
$\begin{array}{l}\text { Adjuvant } \\
\text { treatment }\end{array}$ & \\
\hline yes & 3 & 4 \\
\hline no & 15 & 21
\end{tabular}

Neck recurrence

$\mathrm{OR}=1.05(95 \% \mathrm{Cl}: 0.2043$ to $5.3971 ; \mathrm{p}=0.95)$

$\begin{array}{lll}\text { yes } & 0 & 0 \\ \text { no } & 18 & 25 \\ \text { Total } & 18 & 25\end{array}$

Legends: END, elective neck dissection; SLNB, sentinel lymph node biopsy; OR,odds ratio; CI confidence interval; SD, standard deviation; Site, site of primary tumor; pT1 pT2, histopathological stage of lesion AJCC 8th Edition; ys, years

SN was identified in all patients of SLNB group and harvested by gamma probe.

There was a preponderance of men (91\%), with a similar distribution between the groups (OR = $0.70,95 \% \mathrm{Cl}: 0.0886$ to $5.4649 ; \mathrm{p}=0.73$, Table 1 ). The tumor $\mathrm{T}$ stage and site distribution of patients in each group were similar ( $\mathrm{OR}=0.90 ; 95 \% \mathrm{Cl}$ : 0.2141 to $3.8236 ; \mathrm{p}=0.89)$ as shown in Table 1. 
The average age of patients in the SLNB group was 58.9(SD 5.4y) years and, in the END, was 58.1(SD $6.4 y)$ years; there was no significant difference between groups $(p>0.05)$. The length of follow-up in both groups was from 5 to 8 years with an average of $6.7 y$ and 5.8 y for SLNB and END, respectively (SD: SLNB 1.3y and 2.2y END) years at the closure of study without significant difference in both groups( $p>$ $0.05)$.

In $8 \%$ of SLNB cases and $15 \%$ of END group included in this study received postoperative radiation therapy due to the presence of positive margins, perineural invasion, or vascular emboli without statistical difference.

In this study's cohorts, none recurred in the SLNB group nor the END group, respectively, without a statistical difference between these recurrences rates. All patients were alive without disease.

\section{Discussion}

Literature produced extensively regarding SLNB technique for SCC of the oral cavity. Many trials and meta-analyses were recently published ${ }^{17-22,30}$. The negative predictive value of SLNB ranges from 90 to $100 \%$ for early-stage oral cancer. Step serial section and immunohistochemistry play a vital role in detecting micrometastases in SLNB evaluation, becoming more sensitive than conventional evaluation of neck dissection specimen ${ }^{17-22}$.

Almost $80 \%$ of patients with early-stage SCC of oral cavity submitted to END were pathologically negative. They could be identified on SLNB technique avoiding unnecessary neck dissection with a low rate of false-negative cases ${ }^{23-25}$. The prevailing view regarding END is that it should be performed in a patient with a cNO only if the risk of occult metastasis is higher than $20 \%{ }^{30-32}$. However, negative SNLB with a false-negative rate of 3 to $5 \%$ poses END unnecessary in these cases, as this risk is lower than the $20 \%$ considered a threat.

Prospective studies comparing postoperative complications and quality of life in SCC of the oral cavity and oropharynx submitted to either SLNB or END observed fewer complications and improved quality of life in the SLNB group $32,33,34$.

Although the high rate of sensitivity and negative predictive value of SLNB in oral cancer, no studies compare the rate of neck recurrence in SLNB and END with pathologically negative nodes in large prospective randomized trials like melanoma studies. Only one study compared a large retrospective cohort of patients of a database from the National Cancer Data Base without pairing both groups of patients ${ }^{35}$. Other two multicenter prospective trials observed a non-inferiority of SLNB over END regarding recurrence free, disease specific and overall survival, but not all patients had a longer follow-up ${ }^{36-37}$. Our study was the first to evaluate the recurrence rate between SNB and END groups with a longer follow-up, with a proposal of pairing patients statistically. We observed that both the SLNB and END groups had no recurrences in the neck with the same recurrence rates, i.e., $0 \%$, suggesting the unnecessary elective neck 
dissection when the sentinel lymph node is negative. This low rate of recurrence could be due to small number of cases or adjuvant treatment could be contributed to this rate. But when entire neck dissection specimen is evaluated with extensive pathological evaluation, when it comes pathologically negative it is truly negative leading to a low rate of regional recurrences. With a shallow rate of false-negative cases of $2 \%$ even after an extensive evaluation of these non-sentinel lymph nodes with step serial section and immunohistochemistry ${ }^{38}$, if these micrometastases recur, this rate of recurrence is still comparable to neck recurrence after selective neck dissection with histopathological negative necks. Considering most patients would have histopathological negative necks, it would be possible to select which patient will need neck dissection and who will not need it to save every negative sentinel lymph node ${ }^{39}$. The only disadvantage of the SLNB technique would be performing two-step surgery in a positive sentinel node. Still, this situation would occur in the minority of patients, and a two-week interval will resolve the problem after a complete pathological evaluation of the specimen. This two-step surgery will decrease with real-time rapid quantitative reverse transcription PCR of lymph node with results in 30 minutes with more than $97 \%$ accuracy reaching even $100 \% 40,41$. For more evidence of the reliability of SLNB regarding recurrence and survival, we will need more multicenter prospective randomized trials, with longer followup. Negative predictive value and sensitivity are very high for early-stage oral cancer in all studies of SLNB. However, the sample size of this study is small, representing a major weakness of our study. But given the nature of the research and prospective studies' toughness with large samples, particularly regarding early-stage oral cancer patients our study could, also, fill the gap of comparison results of SNLB and END with pathological negative nodes. It seems an excellent option to avoid END when sentinel lymph node comes out as negative after comprehensive pathological evaluation, with less morbidity and high cost-effectiveness.

\section{Conclusion}

END may be unnecessary in the early stage, $\mathrm{T} 1 / \mathrm{T} 2$ oral cavity SCC when sentinel lymph node comes out as negative after extensive pathological evaluation with immunohistochemistry and step serial section.

\section{Declarations}

Conflict of Interest: Nothing to declare.

Financial disclosure: Nothing to declare.

Source of funding: none

Informed consent was obtained from all patients.

All data and material are available. The datasets during and/or analysed during the current study available from the corresponding author on reasonable request. 
Ethical Approval was obtained by our institutional review board Ethical Committee of State University of Campinas attached

Competing interests: none

Authors' contributions: ANC, ECE, AA, CTC: conception and design and analysis and interpretation of data. GMC, MK: drafting and acquisition of data

Acknowledgements: none

\section{References}

1. Shah JP, Andersen PE. The impact of patterns of nodal metastasis on modifications of neck dissection. Ann Surg Oncol.1994; Nov:1521-32.

2. Rinaldo A, Ferlito A, Silver CE. Early history of neck dissection. Eur Arch Otorhinolaryngol. 2008;265:1535-8.

3. Byers RM. Modified neck dissection: a study of 967 cases from 1970 to 1980 . Am J Surg. 1985;150:414-21.

4. Shah JP. Patterns of cervical lymph node metastasis from squamous cell carcinoma of the upper aerodigestive tract. Am J Surg. 1990;160:405.

5. Kowalski LP, Magrin J, Waksman G, Santo GF, Lopes ME, de Paula RP, et al. Supraomohyoid neck dissection in the treatment of head and neck tumors: survival results in 212 cases. Arch Otolaryngol Head Neck Surg. 1993;119:958-63.

6. Atula TS, Grénman R, Varpula MJ, Kurki TJ, Klemi PJ. Palpation, ultrasound, and ultrasound guided fine-needle aspiration cytology in the assessment of cervical lymph node status in head and neck cancer patients. Head Neck. 1996;18:545-51.

7. Braams JW, Pruim J, Freling NJM, Nikkels PG, Roodenburg JL, Boering G, et al. Detection of lymph node metastases of squamous cell cancer of the head and neck with FDG-PET and MRI. J Nucl Med. 1995;36:211-6.

8. Merrit RM, Willians MF, James TH, Porubsky ES. A meta-analysis comparing computed tomography with physical examination. Arch Otolaryngol Head Neck Surg. 1997;123:149-52.

9. Woolgar JA, Beirne JC, Vaughan ED, Lewis-Jones HG, Scott J, Brown JS. Correlation of histopathologic findings with clinical and radiologic assessments of cervical lymph node metastases in oral cancer. Int J Oral Maxillofac Surg. 1995;24:30-7.

10. Ambrosch P, Kron M, Fischer G, Brinck U. Micrometastases in carcinoma of the upper aerodigestive tract: detection, risk of metastasizing, and prognostic value of depth of invasion. Head Neck. 1995;17:473-9.

11. Mohit-Tarabatai MA, Sobel HJ, Rush BF, Mashberg A. Relation of thickness of floor of mouth stage I and II cancers to regional metastasis. Am J Surg. 1996;152:351-3. 
12. Spiro RH, Huvos AG, Wong GY, Spiro JD, Gnecco CA, Strong EW. Predictive value of tumor thickness in squamous cell carcinoma confined to tongue and floor of the mouth. Am J Surg. 1986;152:34550.

13. D'Cruz AK, Vaish R, Kapre N, Dandekar M, Gupta S, HawaldaR R, et al. Head and Neck Disease Management Group. Elective versus Therapeutic Neck Dissection in Node-Negative Oral Cancer. N Engl J Med. 2015;373:521-9. doi:10.1056/NEJMoa1506007.

14. Ren ZH, Xu JL, Li B, et al. Elective versus therapeutic neck dissection in node-negative oral cancer: Evidence from five randomized controlled trials. Oral Oncol. 2015;51:976-81. doi:10.1016/j.oraloncology.2015.08.009.

15. Stoeckli SJ, Pfaltz M, Ross GL. The second international conference on sentinel node biopsy in mucosal head and neck cancer. Ann Surg Oncol.2005;12: 919-24.

16. Devaney KO, Rinaldo A, Rodrigo JP. Sentinel node biopsy and head and neck tumors-where do we stand today? Head Neck. 2006;28:1122-31.

17. Paleri V, Rees G, Arullendran P. Sentinel node biopsy in squamous cell cancer of the oral cavity and oral pharynx: a diagnostic meta-analysis. Head Neck. 2005;27:739-47.

18. Thompson CF, St John MA, Lawson G, Grogan T, Elashoff D, Mendelsohn AH. Diagnostic value of sentinel lymph node biopsy in head and neck cancer: a meta-analysis. Eur Arch Otorhinolaryngol. 2013;270:2115-22.

19. Civantos FJ, Zitsch RP, Schuller DE, Agrawal A, Smith RB, Nason R, et al. Sentinel Lymph Node Biopsy Accurately Stages the Regional Lymph Nodes for T1-T2 Oral Squamous Cell Carcinomas: Results of a Prospective Multi-Institutional Trial. J Clin Oncol. 2010;28:1395-400.

20. Schilling C, Stoeckli SJ, Haerle SK, Broglie MA, Huber GF, Sorensen JA, et al. Sentinel European Node Trial (SENT): 3-year results of sentinel node biopsy in oral cancer. Eur J Cancer. 2015;51:2777-84. doi:10.1016/j.ejca.2015.08.023.

21. Liu M, Wang SJ, Yang X, Peng H. Diagnostic Efficacy of Sentinel Lymph Node Biopsy in Early Oral Squamous Cell Carcinoma: A Meta-Analysis of 66 Studies. PLoS One. 2017; 20: e0170322. doi: 10.1371/journal.pone.0170322. eCollection 2017.

22. Yang Y, Zhou J, Wu H. Diagnostic value of sentinel lymph node biopsy for cT1/T2N0 tongue squamous cell carcinoma: a meta-analysis. Eur Arch Otorhinolaryngol. 2017;274:3843-52. doi:10.1007/s00405-017-4740-3.

23. Werner JA, Dünne AA, Ramaswany A, Dalchow C, Behr T, Moll R, Folz BJ, et al. The sentinel node concept in head and neck cancer: solution for the controversies in the N0 neck? Head Neck. 2004;26:603-11.

24. Tschopp L, Nuyens M, Stauffer E, Krause T, Zbären P. The value of frozen section analysis of the sentinel lymph node in clinically NO squamous cell carcinoma of the oral cavity and oropharynx. Otolaryngol Head Neck Surg. 2005;132:99-102.

25. Kovács AF, Landes CA, Hamscho N, Risse JH, Berner U, Menzel C. Sentinel node biopsy as staging tool in a multimodality treatment approach to cancer of oral cavity and the oropharynx. Otolaryngol 
Head Neck Surg. 2005;132:570-6.

26. Spiro RH, Morgan GJ, Strong EW, Shah JP. Supraomohyoid neck dissection. Am J Surg. 1996;172:651-53.

27. Strong EW. Preoperative radiation and radical neck dissection. Surg Clin North Am. 1969;49:271-76.

28. Ganly I, Goldstein D, Carlson DL, Patel SG, O'Sullivan B, Lee N, et al. Long-Term Regional Control and Survival in Patients With "Low-Risk," Early Stage Oral Tongue Cancer Managed by Partial Glossectomy and Neck Dissection Without Postoperative Radiation. The Importance of Tumor Thickness. Cancer. 2013;119:1168-76.

29. Amin MB, Edge S, Greene F, Byrd DR, Brookland RK, Washington MK et al, editors. (2017) AJCC Cancer Staging Manual (8th edition). Springer International Publishing: American Joint Commission on Cancer.

30. Stoeckli SJ, Alkureishi LW, Ross GL. Sentinel node biopsy for early oral and oropharyngeal squamous cell carcinoma. Eur Arch Otorhinolaryngol. 2009;266:787-93.

31. Civantos FJ, Stoeckli SJ, Takes RP, Woolgar JA, de Bree R, Paleri V, et al. What is the role of sentinel lymph node biopsy in the management of oral cancer in 2010? Eur Arch Otorhinolaryngol. 2010;267:839-44.

32. Murer K, Huber GF, Stoeckli SJ. Comparison of morbidity between sentinel node biopsy and elective neck dissection for treatment of the NO neck in patients with oral squamous cell carcinoma. Head Neck. 2011;33:1260-4.

33. Hernando J, Villarreal P, Alvarez-Marcos F, Gallego L, García-Consuegra L, Junquera L. Comparison of related complications: sentinel node biopsy versus elective neck dissection. Int J Oral Maxillofac Surg. 2014;43:1307-12. doi:10.1016/j.ijom.2014.07.016.

34. Govers TM, Schreuder WH, Klop WM, Grutters JPC, Rovers MM, Merkx MAW, et al. Quality of life after different procedures for regional control in oral cancer patients: cross-sectional survey. Clin Otolaryngol. 2016;41:228-33. doi:10.1111/coa.12502.

35. Cramer JD, Sridharan S, Ferris RL, Duvvuri U, Samant S. Sentinel Lymph Node Biopsy Versus Elective Neck Dissection for Stage I to II Oral Cavity Cancer. Laryngoscope. 2019;129:162-9. doi:10.1002/lary.27323.

36. Garrel R, Poissonnet G, Plana AM, Fakhry N, Dolivet G, Lallemant B,et al. Equivalence randomized trial to compare treatment on the basis of sentinel node biopsy versus neck node dissection inoperable T1-T2N0 oral and oropharyngeal cancer. J Clin Oncol. 2020;38:4010-8. doi:10.1200/JC0.20.01661.

37. Hasegawa Y, Tsukahara K, Yoshimoto S, Miura K, Yokoyama J, Hirano S, et al: Neck dissections based on sentinel lymph node navigation versus elective neck dissections in early oral cancers:A randomized, multicenter, non-inferiority trial. J Clin Oncol. 2021 Apr 20:JC02003637. doi: 10.1200/JC0.20.03637. Online ahead of print. PMID: 33877855.

38. Christensen A, Bilde A, Therkildsen MH, Mortensen J, Charabi B, Kirkegaard J, et al. The Prevalence of Occult Metastases in Nonsentinel Lymph Nodes after Step-Serial Sectioning and 
Immunohistochemistry in cNO Oral Squamous Cell Carcinoma. Laryngoscope. 2011;121:294-8.

39. O'Connor R, Pezier T, Schilling C, McGurk M. The relative cost of sentinel lymph node biopsy in early oral cancer. J Craniomaxillofac Surg. 2013;41:721-7.

40. Ferris RL, Xi L, Raja S. (2005) Molecular Staging of Cervical Lymph Nodes in Squamous Cell Carcinoma of the Head and Neck. Cancer Res.2005; 65:2147-56.

41. Garrel R, Dromard M, Costes V. (2006) The Diagnostic Accuracy of ReverseTranscription-PCR Quantification of Cytokeratin mRNA in the Detection of Sentinel Lymph Node Invasion in Oral and Oropharyngeal Squamous Cell Carcinoma: A Comparison with Immunohistochemistry. Clin Cancer Res.2006;12: 2498 - 505. 